\title{
Effect of Interface Bond Condition on Pavement Life: A Case Study on National Highway-5, Bangladesh
}

\author{
Md. Asaduzzaman ${ }^{1}$, Nagato Abe ${ }^{2}$ and Kimitoshi Hayano ${ }^{3}$ \\ ${ }^{1}$ Masters Research Student, Infrastructure Management Program, Yokohama National University, Japan \\ (79-5, Tokiwadai, Hodogaya-ku, Yokohama, 240-0066, Japan) \\ E-mail:sceazer131@gmail.com \\ ${ }^{2}$ Fellow Member of JSCE, Lecturer of Fukuoka University, General Manager, Technical Dept., Toa Road Corporation \\ (7-8-5, Akasaka Minato-ward, Tokyo 107-0052, Japan) \\ E-mail:n_abe@toadoro.co.jp \\ ${ }^{3}$ Regular Member of JSCE, Professor, Institute of Urban Innovation, Yokohama National University \\ (79-5, Tokiwadai, Hodogaya-ku, Yokohama, 240-8501, Japan)
}

\begin{abstract}
This paper presents the reasons of interface bond failures on National Highway-5 (N5) and remedial measures to counter those failures. Based on field investigation and assumptions, the pavement was analysed by General Analysis of Multi-layered Elastic System (GAMES) software. Different interface conditions ranging from full bond to full slip were analysed by GAMES. Results indicate that combination of interface bond condition and overloading can reduce pavement life significantly. Analysis also suggests that interface bonding condition between two asphalt layers can be improved by converting lower asphalt layer into granular base layer or combining two asphalt layers into single asphalt layer. These measures were found to be applicable for N5 in Bangladesh.
\end{abstract}

Key words: Interface bond failure, GAMES, Full bond, Full Slip, Pavement life, National Highway.

\section{Introduction}

Asphalt pavement consists of several material layers. These layers are connected with each other by certain degree of interface bonding. Distribution of pavement stress and strain is influenced by interfaces bonding condition. According to Ziari and Khabiri (2007), interface condition between asphalt wearing and surface course can dramatically change strain pattern in two layers and increases vertical strain at the top of subgrade ${ }^{1)}$. Pavement fatigue and rutting lives are calculated from this traffic induced strain. Therefore, interface bonding condition can reduce pavement life significantly. Pavement life can be reduced up to $80 \%$ in case of de-bonded between bituminous base course and granular base ${ }^{2)}$.

National highways (N1 to N8, length $4780 \mathrm{~km}$ ) are regarded as the backbone of Bangladesh economy. The surface condition of Highways has to be maintained at a certain level for national economic growth. Roads and Highways Department (RHD) maintains those National Highways (NHs) through annual Periodic Maintenance Programs (PMP). PMP recommend $50-80 \mathrm{~mm}$ bituminous overlay (BO) or double bituminous surface treatment (DBST) with consideration of surface condition ${ }^{3)}$. If surface condition is not good, BO is suggested otherwise DBST.

According to Highway Development and Management-4 (HDM-4) report, design life of BO work is five years ${ }^{3)}$. But, previous works quality gave impression to RHD that bituminous overlay work's life would not be more than two years. So, it is reality that BO work will sustain up to two years (expected design period). After two years, pavement demands another BO work.

Due to repeating BO works, slippage failures between two asphalt layers are very common in $\mathrm{NHs}$ in Bangladesh. Currently, slippage failures are found at different sections on N5. However, the real reasons of failure have not been investigated yet. So, this study will focus on the reasons of failure that happened on $\mathrm{N} 5$ and suggest probable measures to counter this problem.

\section{Overview of National Highway-5 (N5)}

N5 connects the northern part of Bangladesh to capital Dhaka with a length of $500 \mathrm{~km}$ as shown in 
figure 1. Recently, several slippage failures occurred on N5. Local Reference Point (LRP) 243 to $248 \mathrm{~km}$ from Dhaka is one of the failure portion as shown in figure 1 .

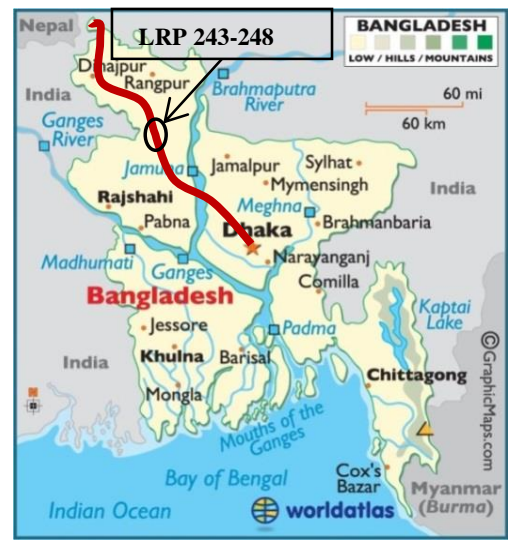

Figure 1: N5 connects to northern part of Bangladesh

This portion was constructed by Road Rehabilitation Improvement and Maintenance Project (RRIMP) in 1992-93 as shown in figure 2.

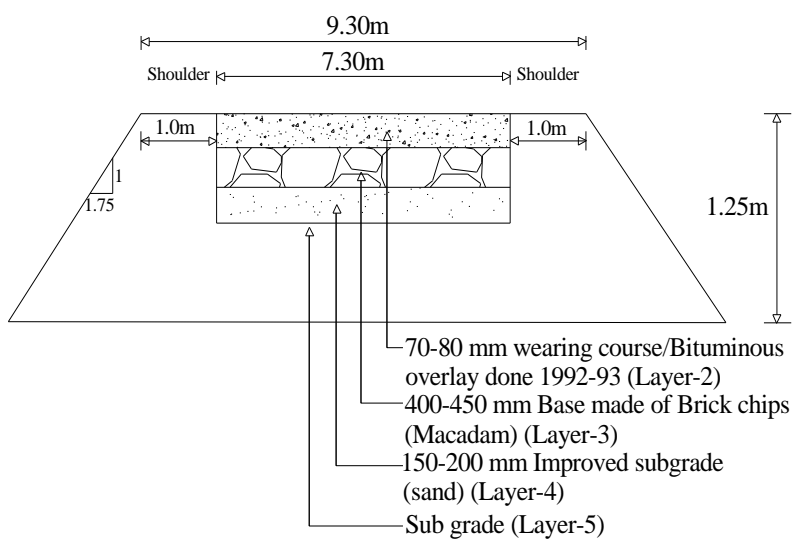

Figure 2: N5 road cross-section constructed in 1992-93

This affected portion has two parts; LRP 243 to 245 $\mathrm{km}$ and LRP 245 to $248 \mathrm{~km}$ are part-1 and part-2 respectively. Due to wear and tear, part-1 and part-2 experienced minor and major cracks respectively. In order to maintain road in service condition, $25 \mathrm{~mm}$ DBST work in 2007-08 and 50mm (BO) work in 2008-09 were done on part-1 and part-2 respectively under PMP. From 2007-08 to 2013, RHD did minor maitenance works on both parts such as poth-holes repair, seal coat and patch repairs.

Despite these maintenance works, the road surface again experienced major cracks on both parts as shown in figure 3. In January 2014, 50mm (BO) work (layer-1) was done from LRP 243 to $248 \mathrm{~km}$ (both parts) under PMP as shown in figure 4.

\section{Damage Observed from LRP 243 to $248 \mathrm{~km}$}

After three to four months of BO work,
March/April 2014, at the beginning of rainy seasons, premature failures (approximately 5\% of pavement area) occurred in some portions of pavement. In May/June 2014, at the mid of rainy seasons, failures were observed widely (approximately 30\% of pavement areas). Generally, from March to June average temperature varies from $31^{\circ} \mathrm{c}$ to $33^{\circ} \mathrm{c}$.

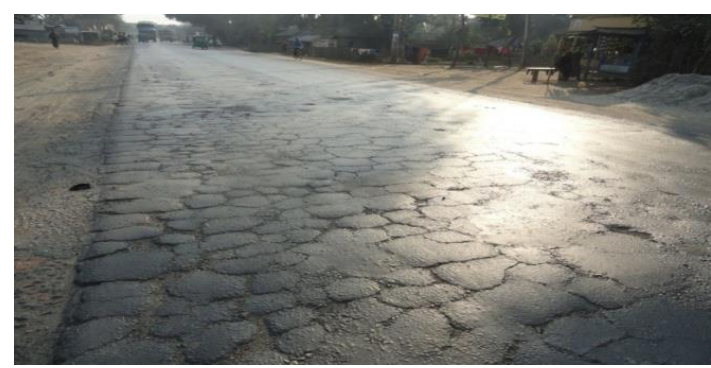

Figure 3: Cracks on pavement surface $9.30 \mathrm{~m}$

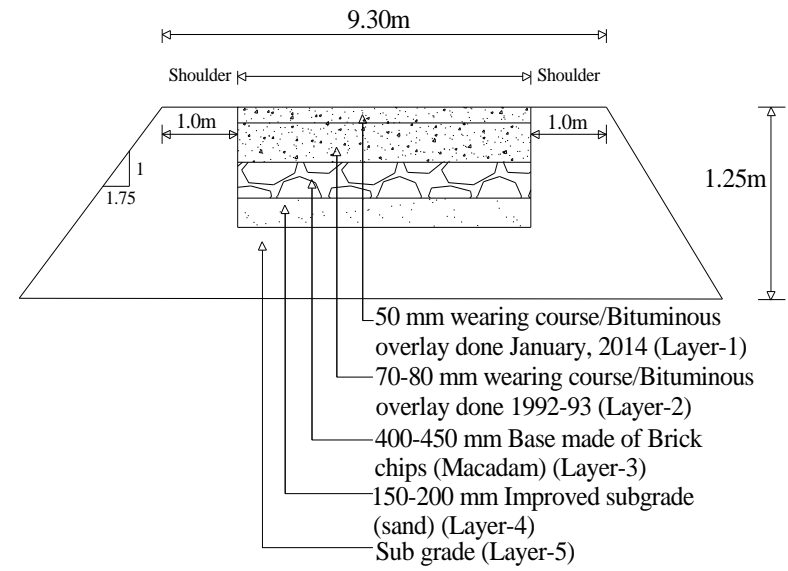

Figure 4: Layer-1 constructed over layer-2 in January 2014

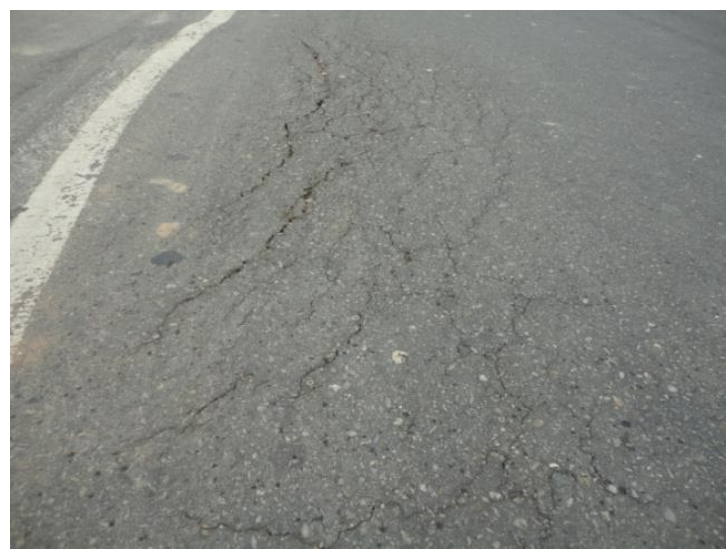

Figure 5: Longitudinal sliding on pavement

By observing failures trend, it can be assumed that pavement sustained up to six months. Actually, the pavement was supposed to sustain up to expected design period (2 years). But, pavement life was reduced to zero by six months that means pavement surviving life was $25 \%$ of expected design period (2 years). The following damages were observed in affected portions.

1. The section was observed longitudinal sliding on surface as shown in figure 5 . 
Localised sliding phenomena occured along wheel tracks.

2. An investigation was conducted on failure portion by RHD as shown in figure 6. During excavation, it seemed that new wearing course (layer-1) was softter than old bituminous layer (layer-2). It was also observed that layer-1\&2 were not bonded sufficiently. There was a clear separation between new and old layers as shown in figure 7. A thin muddy layer was created on opposite face of layer-1. This thin muddy layer made opposite face smooth and frictionless as shown in figure 8. In contrast, when layer- 2 was dug, the top face of macadam (reddish face) firmly adhered to the bottom of layer-2 as shown in figure 9. It seemed that layer- $2 \& 3$ were bonded properly.

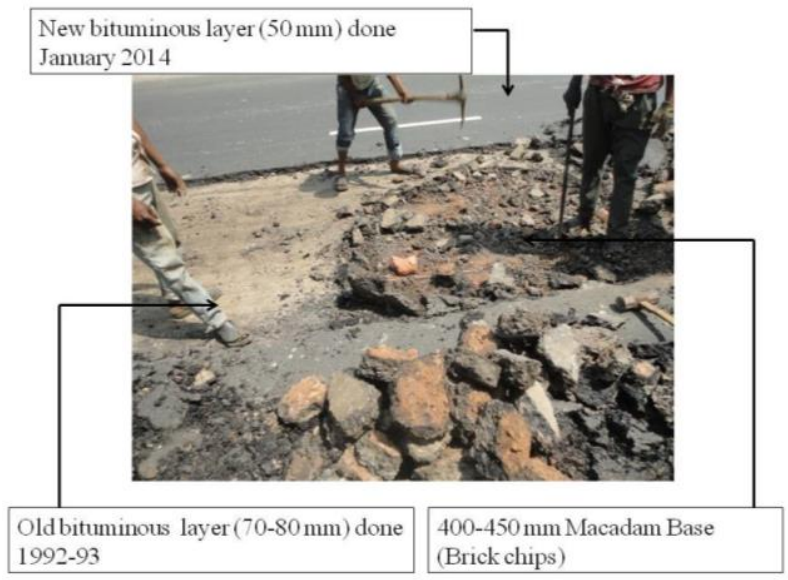

Figure 6: Excavation done in failure portion

3. Further investigation was conducted on layer-3 which was brick macadam base. The base looked wetted. The size of brick particle were changed and turned into finner particles as shown in figure 10. During digging macadam base, it seemed it was too hard to penetrate the shovel.

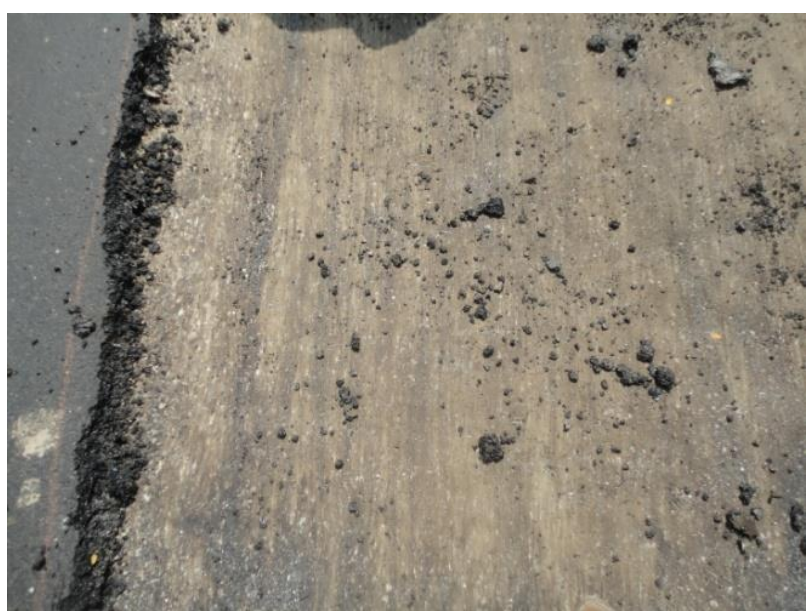

Figure 7: Separation of layer-1\&2

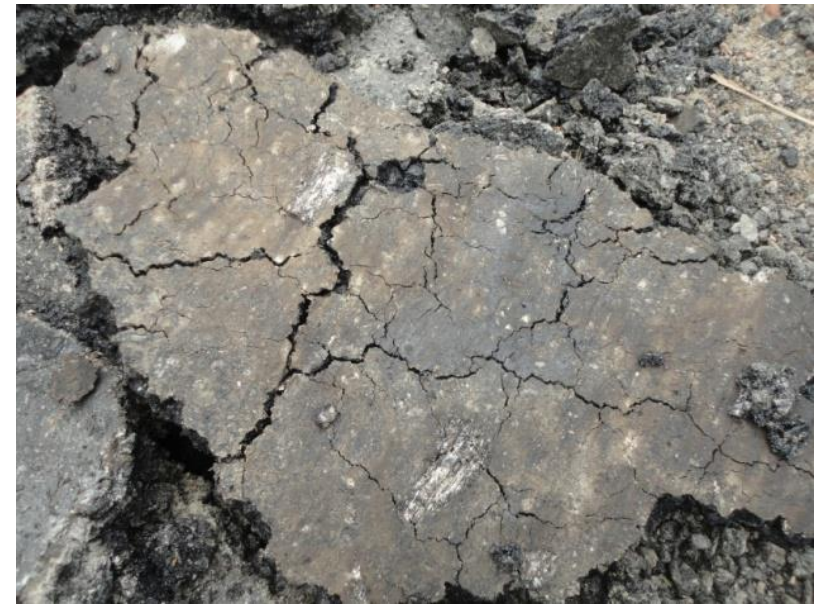

Figure 8: Opposite face of layer-1(thin muddy filmy)

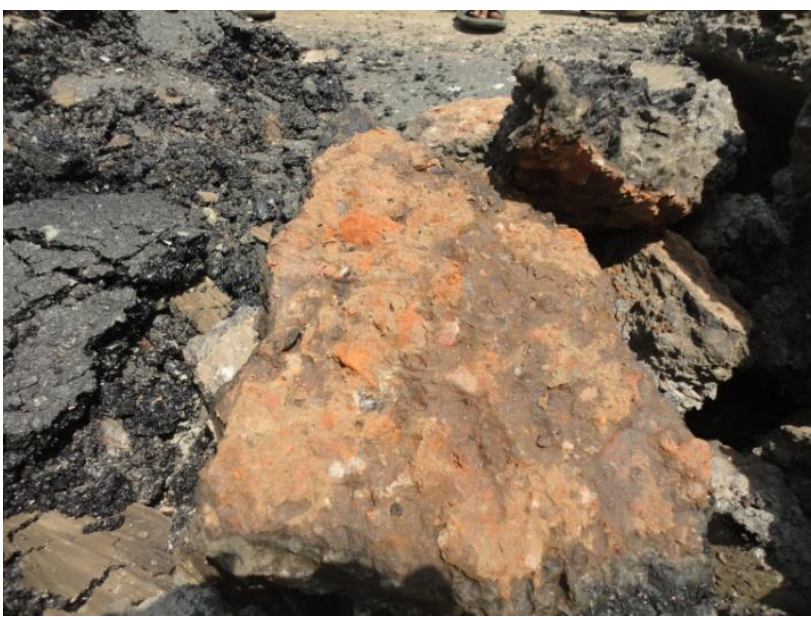

Figure 9: Opposite face of layer-2

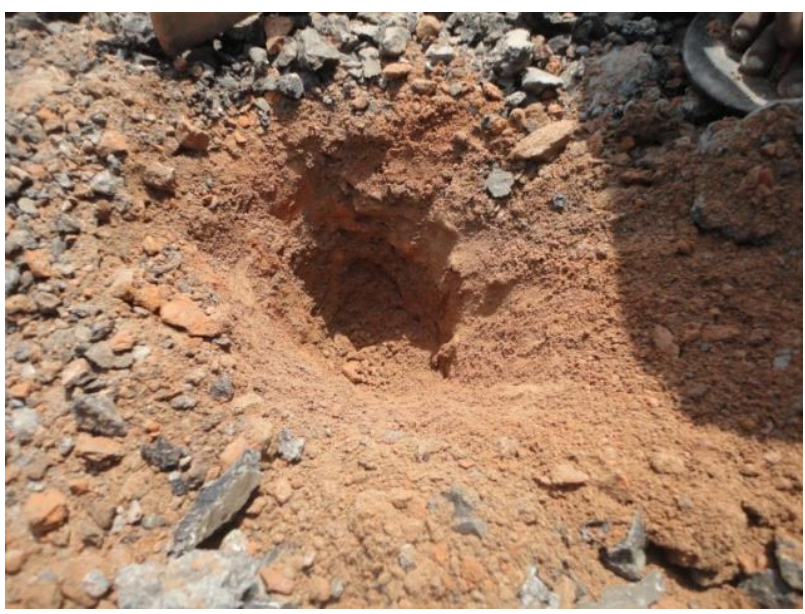

Figure 10: Damp and wet macadam base contains finer particle

\section{Assumptions of Damage}

First: Old bituminous surface (layer-2) was cracked. Water infiltrated through layer-2 and reached to layer-3. Layer-3 which consisted of more finer particles could not drain out water properly. So water was trapped into both layer-2\&3. Even though 
weather was dry (investigation period), the top of layer-3 looked dampish. When new hot bituminous layer (layer-1) was laid over layer-2, water that was trapped into layer-2\& 3 came out to the bottom of layer-1 by cappilarity. This water created a thin muddy layer with clay particles that were attached to the top of layer-2 as shown in figure 11. Even blower machine could not clean clay particles from the top of layer-2. This thin muddy layer deactivated tack coat's function and created a frictionless interface condition. Consequently, interface bond failure occurred between layer-1\&2. This interface bond failure redistributes the stress \& strain pattern of pavement. Finally, cracks were developed on surface and made sudden pavement life reduction.

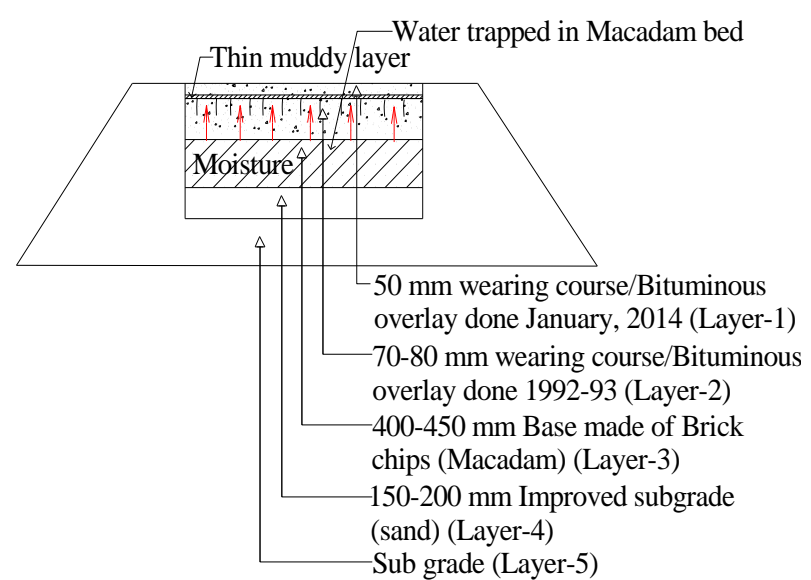

Figure 11: Thin muddy layer created between layer-1\&2

Second: During excavation, it seemed that layer-2 was more stiffened or rigid than layer-1. The rigidity of layer-2 may have some effects on bond failure between two layers. In some portions, layer-2's top surface was smooth as shown previously in figure 7 . In that case, low spraying rate and temperature of tack coat may create poor bonding interface between layer-1\&2.

Third: Overloading is frequently observed in NHs in Bangladesh. Permissible standard axle loading is 8.16 ton. According to Bangladesh Road Master plan (2007), the degrees of axle overloading of all NHs are very high as shown in figure 12 . It reported that on an average 7-8 tonnes, 12 ton and 3 ton axle overloading were observed for medium and heavy trucks and on standard buses respectively ${ }^{4)}$. So, overloading and interface bond failure may be the coupling factor for drastic life reduction of N5.

\section{Analysis of Pavement}

To verify the above mentioned damages assumptions, General Analysis of Multi-layered
Elastic System (GAMES) was used ${ }^{5)}$. First assumption could not be materialized by GAMES because there was no provision for water content input parameter to software. However, GAMES could be helpful to verify other assumptions.

\subsection{Pavement Structure Model}

Pavement that was observed in field consisted of five layers as shown in figure 13.

\subsection{Load Configuration Model}

Standard axle dual wheel load configuration model as shown in figure 14 was used in this analysis. No horizontal load was applied in this model.

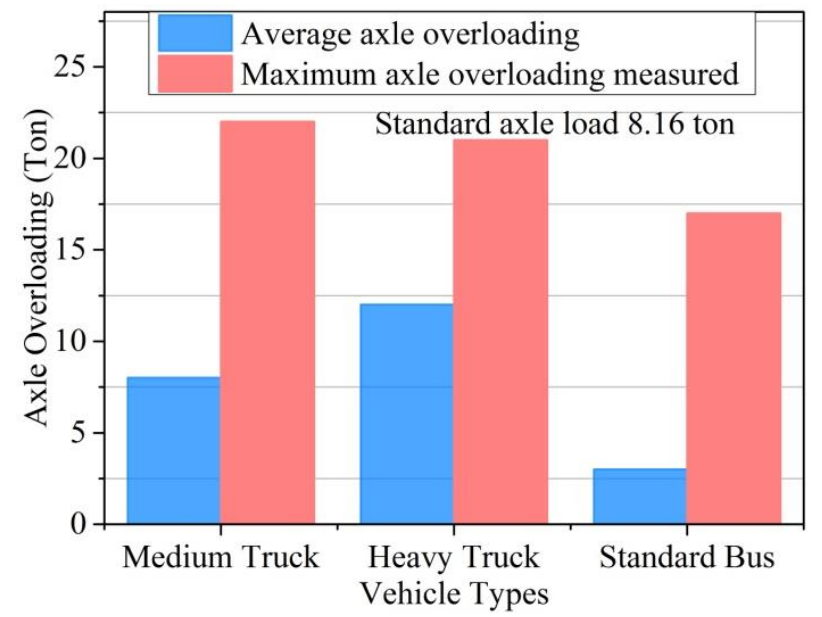

Figure 12: Overloading on NHs in Bangladesh

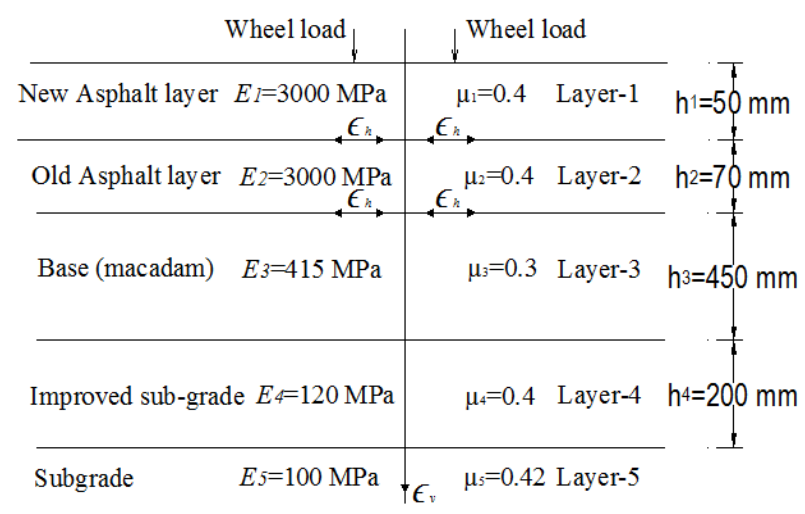

Figure 13: Pavement structure model

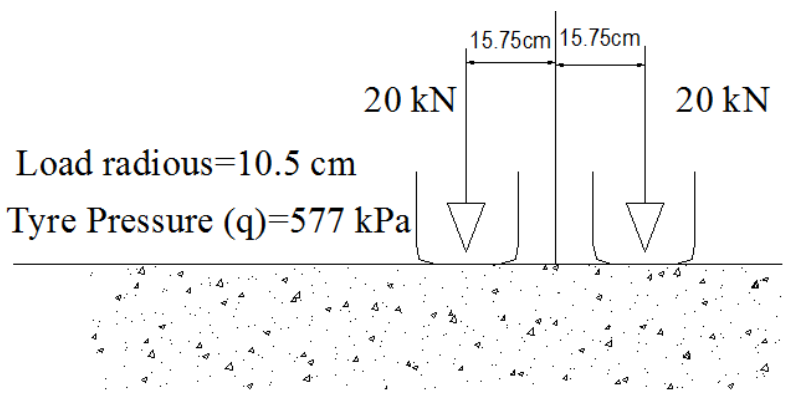

Figure 14: Load configuration model 


\subsection{Interface Condition}

In pavement design, full bond condition is generally considered. But, in practical field, bond condition may range from full bond to full slip that can be accommodated by GAMES. The pavement was analyzed in different interfaces conditions as shown in table 1.

\subsection{Fatigue and Rutting Lives}

Fatigue and rutting model coefficients based on Asphalt Institute were used for pavement life calculations which are given below: $N_{f l}=0.0796 \epsilon_{t}{ }^{-3.291} E_{l}^{-0.854}$ and $N_{f 2}=1.365 E-09 \epsilon_{v}{ }^{-4.477}$ Where, $N_{f l}=$ allowable number of load repetition to prevent fatigue cracking, $N_{f 2=}$ allowable number of load repetition to prevent rutting cracking, $\epsilon_{t}=$ tensile strain at the bottom of asphalt layer, $\epsilon_{v}=$ compressive strain at the top of sub-grade layer, $E_{l}=$ elastic modulus of asphalt layer.

Table 1: Interface condition in this research

\begin{tabular}{|c|l|}
\hline Case & \multicolumn{1}{|c|}{ Interface Condition } \\
\hline A & $\begin{array}{l}\text { All layer's interfaces fully bonded (all layer's } \\
\text { interfaces slip ratio (SR)-0) }\end{array}$ \\
\hline B & $\begin{array}{l}\text { Interface between layers 1\&2 is de-bonded } \\
\text { (SR-0.99 for interface between layer 1\&2). }\end{array}$ \\
\hline C & $\begin{array}{l}\text { Interface between layers 2\&3 is de-bonded } \\
(\text { SR-0.99 for interface between layer 2\&3). }\end{array}$ \\
\hline D & $\begin{array}{l}\text { Interface between layers 1\&2 and 2\&3 } \\
\text { de-bonded (SR-0.99 for interface between layer } \\
1 \& 2 \text { and 2\&3). }\end{array}$ \\
\hline
\end{tabular}

\subsection{Input Parameters}

The pavement was analyzed with the following parameters as shown in table 2. Different types wheel load were observed in Bangladesh. During excavation $2^{\text {nd }}$ layer seemed to be hard. So, $2^{\text {nd }}$ layer modulus was varied. First and second layer were seemed to be separated during excavation. Therefore, different bond conditions were considered in analysis.

Table 2: Input parameters

\begin{tabular}{|c|c|c|}
\hline Definition & Unit & Variables \\
\hline Wheel Load & $\mathrm{kN}$ & $20,25,30,35,40,45$ \\
\hline $\begin{array}{l}\text { Tyre } \\
\text { Pressure (q) }\end{array}$ & $\mathrm{kPa}$ & $\begin{array}{l}577,721,866,1010, \\
1155,1300\end{array}$ \\
\hline $\begin{array}{l}\text { Layer-1 } \\
\text { thickness } \\
\left(\mathrm{h}_{1}\right)\end{array}$ & $\mathrm{mm}$ & $30,40,45,50$ \\
\hline $\begin{array}{l}\text { Layer-2 } \\
\text { Elastic } \\
\text { Modulus }\left(\mathrm{E}_{2}\right)\end{array}$ & $\mathrm{MPa}$ & $\begin{array}{l}600,1200,1800,2400, \\
3000,3600,4200,4800, \\
5400,6000\end{array}$ \\
\hline Slip Ratio & Unit-less & $0,0.2,0.4,0.6,0.8,0.99$ \\
\hline
\end{tabular}

\section{Results and Discussions}

\subsection{Effect of interface conditions on fatigue and rutting lives}

Cases-A to D were analyzed by GAMES to compute horizontal and vertical strain. Horizontal strains are presented on figure 15 with different interface conditions. Figure 15 indicates that interface condition significantly affects horizontal strain. If all layers of pavement are fully bonded (case-A), horizontal strain range is relatively compressive dominated. But for other cases (B, C and $\mathrm{D})$ horizontal strain range is tensile dominated. When interfaces bonding condition are poor (case-B, $\mathrm{C}$ and D), cracks are likely to initiate at the bottom of layer-1; and maximum tensile strain may occur at the bottom of layer-1 (case-B). However, in full bond condition (case-A), maximum tensile strain occurs at the bottom of layer- 2 .

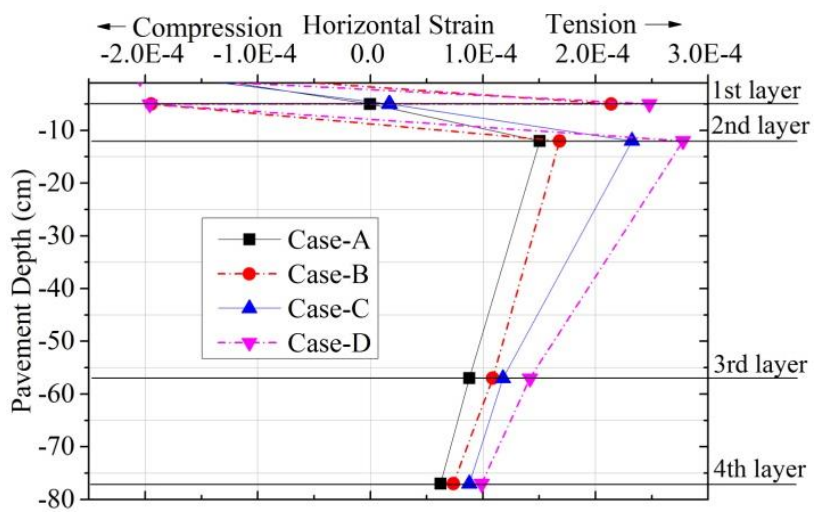

Figure 15: Horizontal strain in different depth of pavement

As fatigue and rutting lives are calculated from strains, interface bonding condition greatly affects pavement life. Figure 16 shows that fatigue and rutting lives are longer for full bonded condition than other cases.

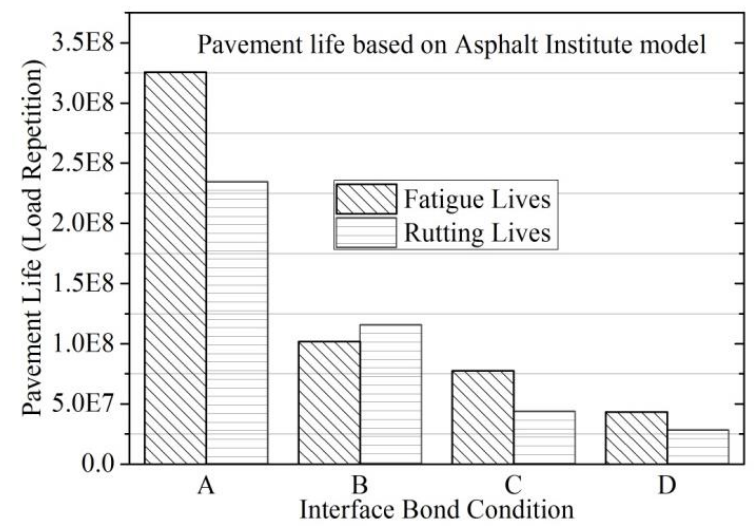

Figure 16: Pavement life for different interface conditions.

It is very short for case-D. For case-B that means when top two asphalt layers are de-bonded, fatigue 
and rutting lives are around $30 \%$ and $50 \%$ of full bond condition (case-A); fatigue lives are shorter than rutting. Fatigue failures occur earlier than rutting that was observed in N5.

\subsection{Effect of $2^{\text {nd }}$ layer's rigidity and interface conditions on fatigue and rutting lives}

Case-A to D were analyzed with changing $2^{\text {nd }}$ layer's rigidity and compared with full bond condition (case-A). Figure 17 indicates that all cases except case-D, both fatigue and rutting lives are increased with increasing stiffness. When $2^{\text {nd }}$ layer rigidity is increased, it allows better load transfer to foundation; results in lower horizontal and vertical strain at the bottom of asphalt layers and at the top of sub-grade respectively. But, for worst condition in pavement (case-D), changing $2^{\text {nd }}$ layer rigidity does not have significant effect on pavement life increment. So, increasing $2^{\text {nd }}$ layer's rigidity (second assumption) cannot be taken as a determining factor for bond failure and responsible for pavement life reduction. In contrast, it can be concluded that when interface bond failure occurs between layer-1\&2, fatigue and rutting lives can be increased with compare to full bond condition by increasing $2^{\text {nd }}$ layer stiffness.

\subsection{Effect of slippage ratio (SR) on fatigue and rutting lives}

From field observation, it seemed that layer-1\&2 were de-bonded. Thus, Case-B interface condition was further analysed with varying SR to observe the effect of partial interface bonding condition on pavement life. Figure 18 indicates that partial bonding condition that could be occurred in real pavement significantly affects fatigue and rutting lives. When, new and old asphalt layers were de-bonded (SR-0.99), pavement fatigue lives reduced more than rutting. The pavement passed through fatigue failures earlier than rutting. The affected portion was also observed fatigue failures. From SR-0 to SR-0.8, pavement life reduction rate was slower than after SR-0.8. After SR-0.8, fatigue and rutting lives of pavement reduced drastically and remained on $30 \%$ and $50 \%$ respectively.

\subsection{Effect of top layer thickness and interface condition on fatigue and rutting lives}

In Bangladesh pavement layer's thickness was measured on average basis. A section may possess below $50 \mathrm{~mm}$ thickness. That is why, case-B was analysed with reduced layer-1 thickness. Figure 19 refers that changing top asphalt layer thickness does not have remarkable effect on rutting lives reduction. But, there was some effects on fatigue lives reduction. Since the study road (N5) experienced premature failure mainly fatigue failures, reduced layer-1 thickness can not be a acceptable reason for drastic life reduction.

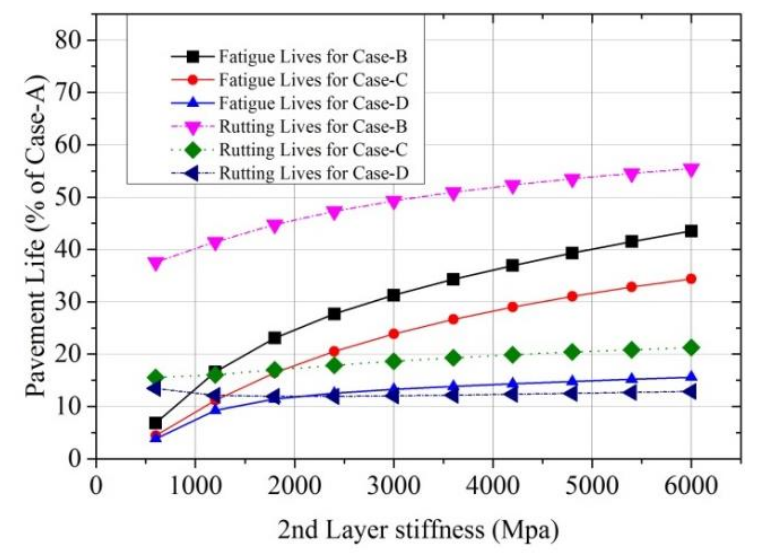

Figure 17: Pavement life with changing 2nd layer stiffness with different interface conditions.

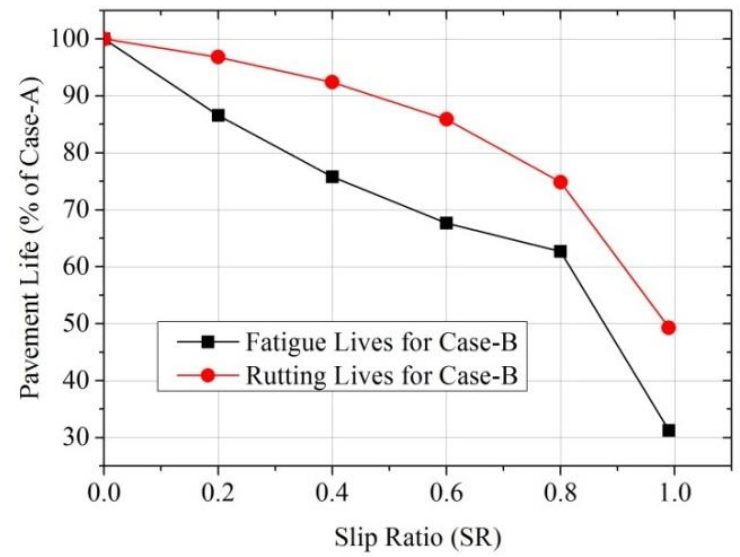

Figure 18: Variation of fatigue and rutting lives with changing interface bonding condition.

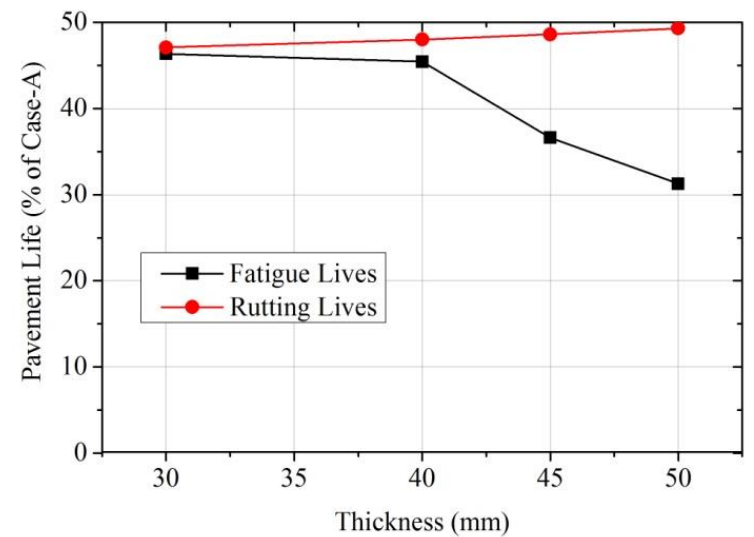

Figure 19: Change of pavement life by reduced layer-1 thickness

\subsection{Effect of overloading and interface bond condition on fatigue and rutting lives}

There are no concrete study about the rate of overloading vehicles. But, overloading vehicles deteriorate pavement an amount of USD 40 million in each year ${ }^{4)}$. The pavement was further analysed by 
coupling of overloading and changing interface bonding condition. Figure $20 \& 21$ indicate that interface bonding condition beteeen $1^{\text {st }}$ and $2^{\text {nd }}$ layer is dominant factors for pavement deterioration at standard axel loading. At standard axle loading (0 ton), fatigue and rutting lives drastically reduced to $31 \%$ and $50 \%$ respectively. In contrast, when pavement experiences overloading, degrees of overloading dominates over bonding contion for pavement deterioration.

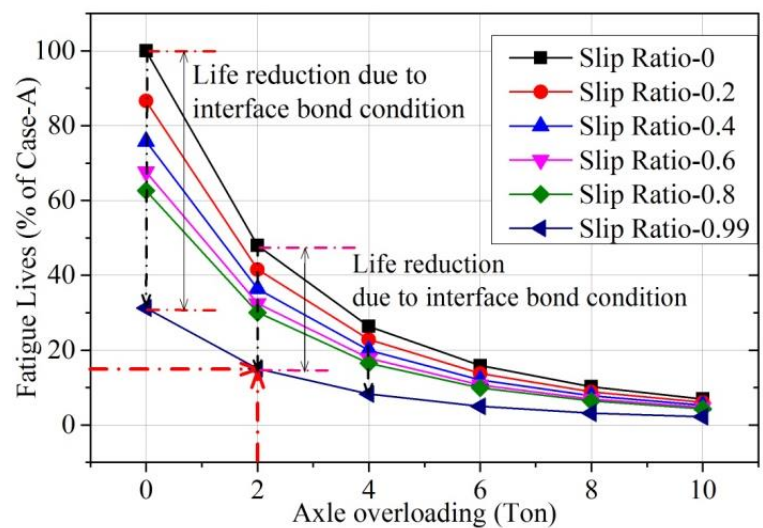

Figure 20: Overloading effect of fatigue lives due to change in interface bonding condition

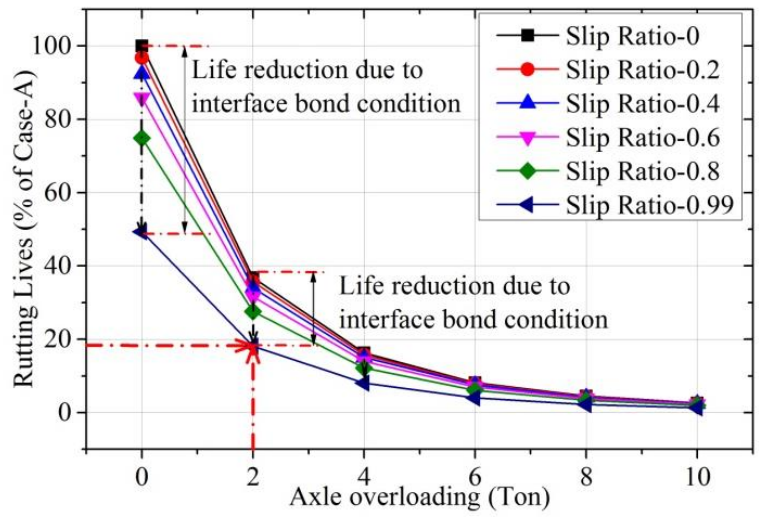

Figure 21: Overloading effect of rutting lives due to change in interface bonding condition

At 2 ton over loading, interface bonding condition is solely responsile for $32 \%$ of fatigue and $18 \%$ of rutting lives reduction. Whereas, it is responsible for only $4 \%$ of fatigue and $1 \%$ of rutting lives reduction at 10 ton overloading. These reduction patterns indicate that pavement life can mostly be affected by overloading whether slippage occurs between $1^{\text {st }}$ and $2^{\text {nd }}$ layer or not. The N5 pavement life reduced to $25 \%$ within 5-6 months. According to figure 20\&21, it can be concluded that at first bond failure between layer- $1 \& 2$ occurred; fatigue and rutting lives reduced to $31 \%$ and $50 \%$ respectively and then average 2 tonnes overloading further reduced fatigue and rutting lives around to $20 \%$. Buses are very common in N5. Standard buses with average 3 tonnes overloading are very frequent in $\mathrm{NHs}$ in Bangladesh $^{4)}$.

\section{Proposed Remedies and Implementation}

Bangladesh's road infrastructure faces severe fund crisis for maintenance works. Due to insufficient fund, the study emphasizes on economic and environmental friendly solution that could be applicable in Bangladesgh road maintenance and management practices.

\subsection{Option-1: Cement base stabilization by recycling layer-2}

Layer-2 should be scarified and seperated particles from lumps and then mixed with cement $2-3 \%$ of cement by volume). Finally, it should be rolled and $50 \mathrm{~mm}$ bituminous overlay layer should be placed over stabilized base (layer-2) as shown in figure 22 . Existing layer-2 materials would be sufficient (except 2-3\% of cement) to prepare stabilized base. This option will enhance bond strength between $1^{\text {st }}$ and $2^{\text {nd }}$ layers. Due to adding cement, increased base stiffness will ensure better load transfer to pavement foundation ${ }^{6)}$. So, fatigue and rutting lives will be increased. Figure 23 indicates that fatigue and rutting life of pavement for option-1 are longer than case A.

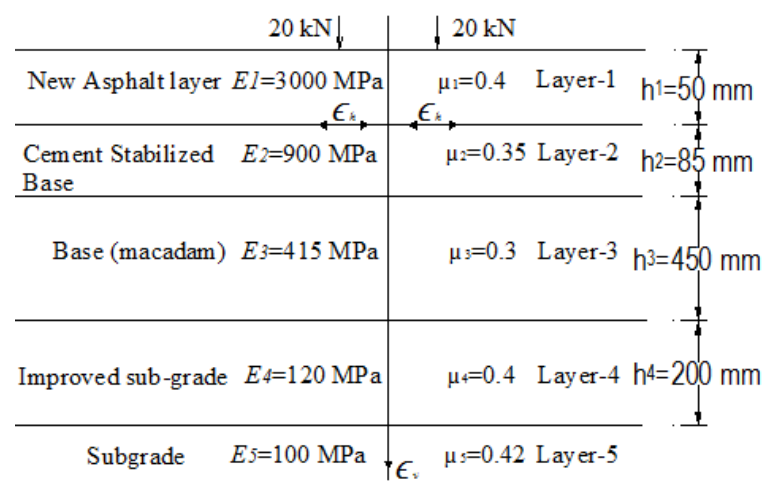

Figure 22: Cement stabilized base (Option-1)

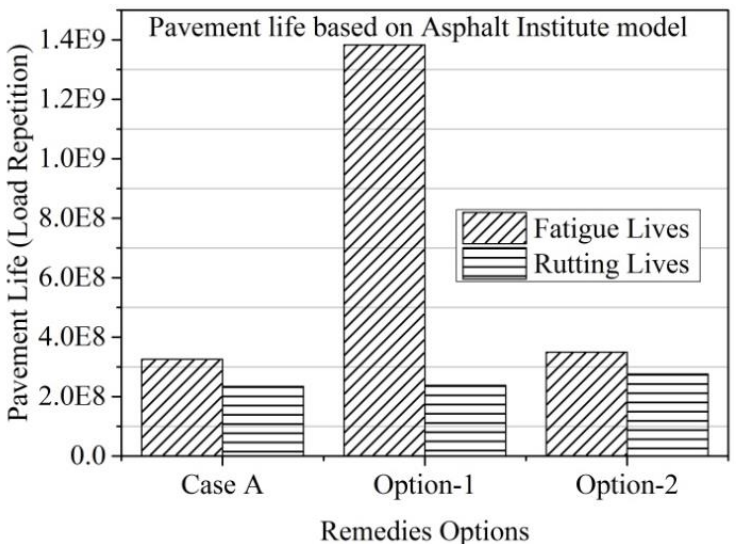

Figure 23: Pavement life of proposed remedies 
Option-1 is now implementing in N5 to resolve bond failure problem between two asphalt layers as shown in figure 24 .

\subsection{Option-2: Recycling the layer-1\&2}

Layer-2 should be scarified and seperated particles from lumps. This old aggregate should be recycled with virgin materials (layer-1 materials) as recycling formulae.

\section{Recycling formulae:}

New Bitumen ( $3 \%$ by weight $)+$ Virgin Stone aggregate $(50 \%$ to $60 \%)+$ Old aggregate $(40 \%$ to $50 \%$ ) + Old bitumen content

Recycling asphalt concrete is laid over macadam base as shown in figure 25. Asphalt layer thickness will be provided as per design requirement. As layer $1 \& 2$ are combined, total asphalt layer thickness will be increased. This increased asphalt layer thickness will reduce horizontal strain and vertical strain of pavement ${ }^{7)}$. So pavement life will be longer than case A as shown in figure 23. Implementation of option-2 is not applicable right now; because Bangladesh RHD does not have pavement recycling technolgy.

Between two options, option-1 would be the most effective solution for two reasons. First, it is cost effective. Material cost can be accommodated from existing layer's materials. Only additional cost for cement, scarifying and grinding of existing layer-2 is required. Finally, existing labor intensive technology can be used for scarifying and separating particles of big lumps of layer-2. Thus, option-1 was selected as a remedial counter measure against bond failure between two asphalt layers on N5.

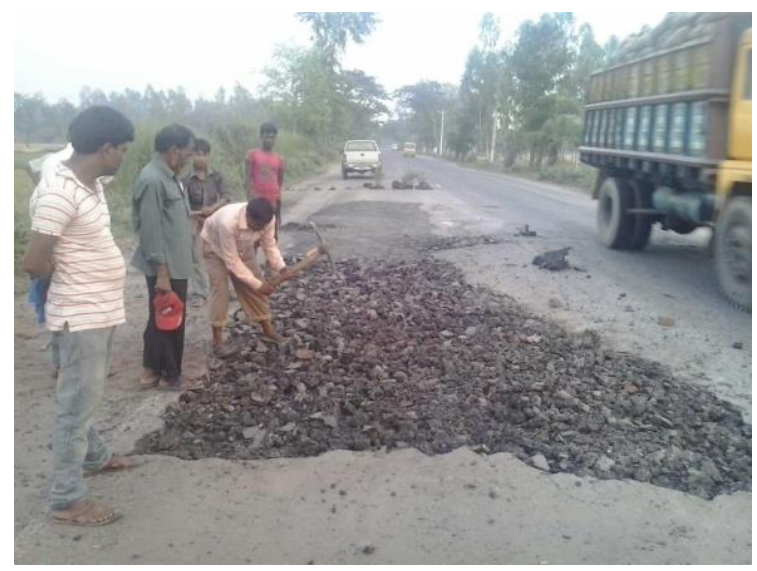

Figure 24: Cement stabilized base (option-1)

Additionaly, proper drainage facilities should be ensured to prevent water infiltration through asphalt surface.

\section{Conclusion}

The following points can be summarized from the study.

1. Interface bonding condition redistributes stress and strain pattern. Strain patterns changes from compressive mood to tensile mood with changing bond conition from full bond to full slip.

2 . Increasing $2^{\text {nd }}$ layer's stiffness does not have remarkable effect on pavement life reduction.

3 . When pavement starts deteriorating by weakening bonding interfaces, fatigue and rutting lives fall drastically to $30 \%$ and $50 \%$ respectively.

4. Overloading is one of the pime factor that diminishes pavement life.

5. Further research is needed to find out the water effect in drastic fallen of pavement life.

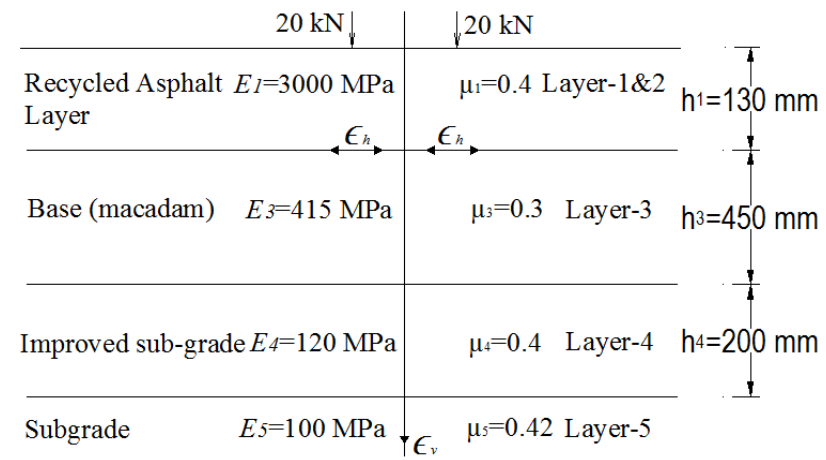

Figure 25: Recycling layer 1 \& 2 (Option-2)

\section{REFERENCES:}

1) Ziari, H. and Khabiri, M. M. : Interface condition influence on prediction of flexible pavement life, Journal of Civil Engineering and Management, Vol. 13:1, pp. 71-76, 2007.

2) Kruntcheva, M. R., Collop, A. C. and Thom, N. H. : Effect of bond condition on flexible pavement performance, Journal of Transportation Engineering, ASCE, Vol. 131:11, 2005.

3) Roads and Highways Department, Bangladesh: Maintenance and Rehabilitation Needs Report, HDM Circle, 2012.

4) Ministry of Communication, Bangladesh: Road Master Plan, Roads and Highways Department, Vol. 1, 2007.

5) Matsui, K., Maina, JW. and Jujinami, K.: Development of Analysis of Multi-Layered Elastic Systems Toward Mechanistic-Emperical Design of Pavement Structures, China Japan $3^{\text {rd }}$ Workshop on Pavement Technologies, Nanjing PR China, November 9-12, 2005.

6) Chai, G. W. K., Oh, E. Y. N. and Balasubramaniam, A. S.: In-situ stabilization of road base using cement- A case study in Malaysia, Retrieved from http://www98.griffith.edu.au/dspace/bitstream/10072/2703/1/29 582_1.pdf.

7) Walubita, L. F. and Ven, M. FC. : Stress and strain in asphalt-surfacing pavements, Action in Transport for the New Millennium, Conference Planners, South Africa, 2000. 